\title{
BMJ Open Survey of the pattern of antibiotic dispensing in private pharmacies in Nepal
}

\author{
Anant Nepal (D , ${ }^{1,2}$ Delia Hendrie, ${ }^{2}$ Suzanne Robinson, ${ }^{2}$ Linda A Selvey ${ }^{3}$
}

To cite: Nepal A, Hendrie D, Robinson S, et al. Survey of the pattern of antibiotic dispensing in private pharmacies in Nepal. BMJ Open 2019;9:e032422. doi:10.1136/ bmjopen-2019-032422

- Prepublication history for this paper is available online. To view these files, please visit the journal online (http://dx.doi. org/10.1136/bmjopen-2019032422).

Received 18 June 2019 Revised 23 August 2019 Accepted 16 September 2019

\section{Check for updates}

(C) Author(s) (or their employer(s)) 2019. Re-use permitted under CC BY-NC. No commercial re-use. See rights and permissions. Published by BMJ.

${ }^{1}$ Executive Board, Nepal Karuna Sewa Samaj, Palpa, Nepal

${ }^{2}$ School of Public Health, Curtin University, Perth, Western Australia, Australia

${ }^{3}$ School of Public Health, The University of Queensland, Brisbane, Queensland, Australia

Correspondence to

Mr Anant Nepal;

anant.nepal@gmail.com

\section{ABSTRACT}

Objectives Private pharmacies are widely established in most low/middle-income countries (LMICs) including Nepal, and are often considered as a patient's first point of contact for seeking healthcare. The aim of this study was to investigate the pattern of antibiotic dispensing in private pharmacies through exit interviews with patients to review their medication information.

Design and setting Cross-sectional study. Data collection was carried out in 60 days at 33 randomly selected private pharmacies in the Rupandehi district of Nepal.

Participants Patients attending private pharmacies $(\mathrm{n}=1537)$.

Main outcome measure The pattern of antibiotic prescribing and dispensing was investigated using WHO's core prescribing indicator, 'the percentage of patients prescribed an antibiotic'. Frequency distributions were presented based on patients' characteristics, sources of antibiotic, registration status of pharmacies and education of the pharmacist or drug retailer, and disease or condition. $\chi^{2}$ tests and regression analysis were applied to explore factors associated with the pattern of antibiotic dispensing. Results Of patients attending private pharmacies, the proportion receiving at least one antibiotic $(38.4 \%)$ was above the WHO recommended value (20.0\%-26.8\%). The most commonly dispensed antibiotics were cefixime (16.9\%) and the third-generation cephalosporins (38.0\%) class. High dispensing rates of antibiotics for selected conditions (eg, respiratory infections, diarrhoeal cases) appeared contrary to international recommendations. The percentage of antibiotic dispensed was highest for patients who obtained their medicines from unlicensed pharmacies (59.1\%). Young people were more likely to receive antibiotics than other age groups.

Conclusions The antibiotic dispensing pattern from private pharmacies in Nepal was high compared with WHO guidelines, suggesting initiatives to reduce inappropriate use of antibiotics should be implemented. The findings of this study may be generalisable to other LMICs in order to assist in developing policies and guidelines to promote more appropriate dispensing and prescribing practices of antibiotics and limit the spread of antibiotic resistance.

\section{INTRODUCTION}

The role of the private sector in healthcare in low/middle-income countries (LMICs) has often been neglected by governments and international public health communities. ${ }^{1}$

\section{Strengths and limitations of this study}

This is the first study to investigate the pattern of antibiotic dispensing in private pharmacies in Nepal.

- Data on dispensing of medications including antibiotics were sourced directly from patients and validated from the dispensed medicines.

- Data were collected from a wide range of private pharmacies including high-end outlets staffed by pharmacists and small outlets staffed by drug retailers without formal health qualifications.

- Exit interviews were based on convenience sampling with interviews conducted between 09:00 and $17: 00$, thus may not be representative of all patients attending private pharmacies.

- Description of diagnoses or conditions by patients were symptom-based rather than disease-specific, which made it difficult to assess appropriate use of antibiotics and whether antibiotic dispensing and prescribing followed the standard guidelines.

However, private pharmacies are widely established in most LMICs, and usually considered as a patient's first point of contact for healthcare and the preferred channel through which to get health services and medicines. ${ }^{2}$ These pharmacies range from high-end outlets to small, rural, road side stalls and can be staffed by fully trained pharmacists or a drug retailer or seller without formal health qualifications. Because of ease of access, more flexible opening hours, availability of cheaper medicines and credit ${ }^{3}$ and personal intimacy, ${ }^{4}$ consumers often tend to use private rather than public facilities. ${ }^{5}$ Further, many patients have neither the time nor money to consult a physician ${ }^{6}$ preferring over-the-counter medicines and healthcare advice. About three in four antibiotic requests and three in five consultations in community pharmacies around the world result in the sale of antibiotics without a prescription. ${ }^{7}$

Non-prescription use of antibiotics is associated with the risk of inappropriate drug use, defined as patients not receiving the appropriate medicines in doses that meet their 
individual requirements, for an adequate duration, and at the lowest cost. ${ }^{8}$ Inappropriate use of medicines is a serious global problem occurring in both developed and developing countries, ${ }^{9}$ with the WHO estimating more than half of all medicines are inappropriately prescribed, dispensed or sold. ${ }^{8}$ This overuse and misuse of antibiotics is one of the main causes of antibiotics becoming ineffective, ${ }^{10}$ thus posing problems relating to treatment failure and other costs to the individual and society. ${ }^{11-13}$

In Nepal, dispensing of medicines is undertaken by pharmacists and drug retailers or sellers and many dispensers have admitted treating patients too by also prescribing medicines. ${ }^{14}$ Pharmacists have 3-5years of pharmacy education ${ }^{14}$; however, drug retailers and sellers include individuals who are only associated with private pharmacies, do not necessarily have formal education in dispensing medicines, but can undertake training and obtain a licence to own and operate a pharmacy from the Department of Drug Administration (DDA), the government body dealing with medicines and their related affairs. ${ }^{15} 16$ Practising healthcare without a license is illegal in $\mathrm{Nepal}^{17}$; however, many unlicensed pharmacies are also operating in remote areas of Nepal. ${ }^{18}$ Little is known about the antibiotic dispensing practices from licensed or unlicensed private pharmacies in Nepal. Previous studies conducted in Nepal that have examined antibiotic dispensing practices from private pharmacies have collected data directly from pharmacists or drug sellers themselves, ${ }^{18} 19$ which may result in inaccurate reporting of dispensing practices. This study has investigated patterns of antibiotic dispensing through exit interviews with patients by reviewing their medication information, thus ensuring collection of reliable information. The findings of this study reveal issues about inappropriate use of antibiotics and can be used as a baseline against which to evaluate initiatives to improve antibiotic dispensing and prescribing practices in the private pharmacy sector in Nepal.

\section{METHODS}

The study was a cross-sectional study conducted in the Rupandehi district of Nepal. This district was selected because it has an almost equal mix of urban and rural residents $^{20} 21$ and a well-represented population of different castes and ethnicities with $>63$ castes/ethnicities residing in the district ${ }^{22}$ out of 126 castes/ethnicities in the country. ${ }^{23}$ Within the district, there is varying access to transport, with good transport only available in urban areas, which is similar to other districts of Nepal.

Private pharmacies were selected based on WHO guidelines. ${ }^{24}{ }^{25}$ Before deciding on the private pharmacies, six survey areas were selected from the seven electoral areas in the district. The district in which the major hospital is located was selected as one survey area and an area with the lowest socioeconomic status as another survey area. An additional four survey areas were randomly selected. One public health facility was selected from each survey area using a list obtained from available records of the District Public Health Office. Altogether, six public health facilities were selected, two each from hospitals, primary healthcare centres and health posts, with the major hospital included as one of the hospitals (as per WHO guidelines). These health facilities were used as the basis for selecting the private pharmacies.

Private pharmacies to include in the study were selected from a list made available by the Nepal Chemists and Druggists Association (NCDA), Lumbini, Nepal. Separate pharmacies and pharmacies attached to private hospitals were included to represent both types. The NCDA list was verified after visiting each selected survey area and updated by deleting any duplicates in the list of pharmacies and adding any missing from the records. In total, 441 private pharmacies were in the NCDA list. Among them, 49 did not exist in the field while 31 were missing on the list. After adjusting the list for these pharmacies, 423 private pharmacies were included in the final list.

As outlined in the WHO guidelines, within each survey area, pharmacies on the final list were grouped according to whether they were located within or beyond $5 \mathrm{~km}$ from each selected public health facility. Within each group in every survey area, pharmacies were assigned a number and then selected for inclusion in the study using a random number generator, with three private facilities selected from the within the $5 \mathrm{~km}$ group and two selected from the $>5 \mathrm{~km}$ group. Three private pharmacies were added to the original sample due to refusal of the initially selected pharmacies to allow data collection on the second day. Each pharmacy was surveyed for 2 days, other than the three that refused data to be collected on the second day and the three replacement pharmacies, which were surveyed for 1 day. Thus, data collection covered 60 days with 33 private pharmacies (2 days per pharmacy for 27 pharmacies and 1 day per pharmacy for 6 pharmacies).

\section{Data collection}

Private pharmacies in Nepal do not follow the practice of keeping patients' records, so exit interviews were conducted with patients who had attended the selected pharmacies. Interviews were conducted from July 2017 to December 2017 from 09:00 to 17:00. The days allocated for data collection were based on the advice of pharmacists to obtain as representative a sample of days as possible. Patients were invited to participate based on convenience sampling, with as many patients as possible who attended the selected pharmacies approached to participate. In total, 1554 patients were approached, with $15(1 \%)$ patients refusing to participate and 1537 patients included in the study. Individuals obtaining medicines on behalf of another person were excluded from the exit interviews as they may not have been able to provide the relevant details about the patient or their condition. In contrast, parents have these details for their children so children attending the pharmacies with their parents were included in the survey. 
Data were collected using the Qualtrics Offline Surveys Application. ${ }^{26}$ Demographic characteristics of the patients for whom the medicines had been bought (age, sex), the disease or condition and sources of antibiotic ${ }^{27}$ (self-medicated, recommended and supplied by a pharmacist or drug retailer without a prescription, prescribed by a doctor and dispensed by a pharmacist or drug retailer, other) were collected. Photographs were taken of the medicines, with no patient identifiers included, and attached to the application. The maximum time taken for the exit interview was $3 \mathrm{~min}$. Prior to the interview, all consumers were informed of the nature of the study and written consent was sought to interviews being conducted. Consent for patients younger than 18 years was sought from the accompanying parent or caretaker.

The principal researcher coordinated data collection and approached respective authorities and health facilities to obtain approval to collect the data, and four Nepali research assistants were engaged in data collection. A training session for research assistants was held prior to embarking on data collection and focused on the aim of the study, the importance of ensuring quality in the data collection and ethical considerations. The research assistants were regularly monitored by the principal researcher to ensure the quality of the data through observation at the study sites and cross-checking of the entered records in the Qualtrics Application.

\section{Data analysis}

The data were imported from the Qualtrics Application to a MS-Excel spreadsheet for cleaning. The cleaned data were transferred to the SPSS statistical software (IBM Corp. Released 2017. IBM SPSS Statistics for Windows V.25.0). Diseases or conditions collected from the interviews were generally described based on symptoms, thus similar symptoms were grouped together. For some analyses, the most commonly occurring groups (such as fever, respiratory symptoms and skin conditions) were separately analysed, with remaining groups combined into those likely to have an infectious cause ('other: infectious'), and those not likely to have an infectious cause ('other: non-infectious'). Antibiotics were also grouped into classes for analysis. ${ }^{28}$ A core prescribing indicator, 'the percentage of patients prescribed an antibiotic' was computed in line with the WHO's standard values. ${ }^{29}$ Descriptive analysis was conducted to show commonly dispensed antibiotics, sources of antibiotic, registration status of pharmacies and education of the pharmacist or drug retailer, and disease or condition. $\chi^{2}$ tests were performed to examine the association between antibiotic dispensing and explanatory variables including sex, age group of patient, sources of antibiotic and registration status of pharmacies and education status of the pharmacist or drug retailer. Logistic regression was also used to examine factors associated with antibiotic dispensing. An interaction term of sources of antibiotic with registration status and education was also examined. The significance level $(\alpha)$ was set at 0.05 for all statistical tests.

\section{Patient and public involvement}

No patients or public were involved in the design and conduct of the study.

\section{RESULTS}

\section{Characteristics of patients and prescription information}

The sample comprised a similar number of male and female respondents, with all age groups relatively well represented (table 1). Just over half of patients (55.2\%) had a prescription from a doctor or health worker, with about one-quarter not having a prescription but purchasing a medicine recommended and supplied by the pharmacist. Almost equal numbers of patients received their medicine from a pharmacist who had a diploma or bachelor's degree in pharmacy (49.6\%) and drug retailers who had completed training from DDA $(46.1 \%)$. The most commonly occurring diseases or conditions were fevers $(18.1 \%)$, coughs $(5.3 \%)$ and respiratory infection $(4.9 \%)$. At least one antibiotic was dispensed in 947 (38.4\%) patient encounters.

\section{Commonly dispensed antibiotics}

Among antibiotics, the most commonly dispensed were cefixime $(16.9 \%)$, amoxicillin $(12.2 \%)$, cefpodoxime $(10.3 \%)$, ampicillin + cloxacillin $(8.7 \%)$ and ciprofloxacin $(8.7 \%)$. Cephalosporins $(38.0 \%)$ were the most commonly dispensed class of antibiotics, followed by penicillins (29.3\%), quinolones $(13.7 \%)$ and marcolides $(8.1 \%)$ (table 2$)$.

The percentage of antibiotics dispensed was highest for those patients for whom the medicine had been prescribed by a doctor or health worker (58\%). It was also highest for patients who obtained their medicines from an unlicensed pharmacy (59.1\%). For several conditions, antibiotics were the most commonly dispensed medicine, including for respiratory infection $(93.3 \%)$, diarrhoea and dysentery $(91.3 \%)$, skin infection $(87.1 \%)$, fever $(70.5 \%)$ and urinary tract infection $(57.9 \%)$.

The class of antibiotics dispensed was relatively similar by sources of antibiotic and registration status and education. Third-generation cephalosporins were the most common class of antibiotics recommended and supplied by a pharmacist or drug retailer without a prescription $(40.7 \%)$ and prescribed by a doctor or health worker $(38.1 \%)$, with antiprotozoals the most common among patients who self-medicated (38.5\%). Cephalosporins were also most commonly dispensed by both drug retailers who had training from DDA $(41.3 \%)$ and those with a diploma or bachelors in pharmacy $(36.1 \%)$. The highest dispensing rate of cephalosporins was for the treatment of fever $(69.5 \%)$, whereas penicillins were common for respiratory infection $(60.8 \%)$, injuries $(78.8 \%)$ and skin infection $(67.2 \%)$ (table 3 ).

\section{Factors associated with antibiotic dispensing}

Across all diseases and conditions, antibiotic dispensing was significantly associated with age group, sources of 
Table 1 Patient characteristics and information related to dispensing of medicines

\begin{tabular}{lll}
\hline Variables & Percentage & $\mathbf{n}_{\mathbf{i}} / \mathbf{n}_{\mathbf{k}}{ }^{*} \boldsymbol{\dagger}$ \\
\hline Sex & & \\
$\quad$ Male & 50.5 & $776 / 1537$ \\
$\quad$ Female & 49.5 & $761 / 1537$ \\
\hline Age group of patient & & \\
$\quad$ Less than 14 years & 19.4 & $298 / 1537$ \\
\hline 15-24 years & 20.2 & $310 / 1537$ \\
25-44 years & 35.0 & $538 / 1537$ \\
\hline 45 and above years & 25.4 & $391 / 1537$ \\
Sources of antibiotic & & \\
$\quad$ Prescribed by a doctor or health & 55.2 & $848 / 1537$
\end{tabular}

worker and dispensed by a

pharmacist or drug retailer

\begin{tabular}{lrr}
$\begin{array}{l}\text { Recommended and supplied by a } \\
\text { pharmacist or drug retailer without } \\
\text { a prescription }\end{array}$ & 26.1 & $401 / 1537$ \\
\hline $\begin{array}{l}\text { Self-medicated } \\
\text { Other (invalid prescription) }\end{array}$ & 13.3 & $205 / 1537$ \\
\hline
\end{tabular}

Registration status/education

\begin{tabular}{|lrr|}
\hline $\begin{array}{l}\text { Licensed/diploma or bachelors in } \\
\text { pharmacy }\end{array}$ & 49.6 & $762 / 1537$ \\
\hline Licensed/training from DDA & 46.1 & $709 / 1537$ \\
\hline Unlicensed/education unknown & 4.3 & $66 / 1537$ \\
\hline Disease or condition $\neq$ & & \\
\hline Fever & 18.1 & $278 / 1537$ \\
\hline Cough & 5.3 & $82 / 1537$ \\
\hline Respiratory infection & 4.9 & $75 / 1537$ \\
\hline Headache & 4.8 & $74 / 1537$ \\
\hline Loss of appetite & 4.7 & $72 / 1537$ \\
\hline Skin infection & 4.6 & $70 / 1537$ \\
\hline Common cold & 4.4 & $68 / 1537$ \\
\hline Injury & 4.4 & $67 / 1537$ \\
\hline Acid peptic disease & 4.3 & $66 / 1537$ \\
\hline Body ache & 4.2 & $65 / 1537$ \\
\hline Heart disease & 4.2 & $64 / 1537$ \\
\hline Fungal infection & 3.8 & $59 / 1537$ \\
\hline Skin disease & 3.7 & $57 / 1537$ \\
\hline Abdominal discomfort & 3.6 & $55 / 1537$ \\
\hline Arthritis and bone pain & 3.3 & $50 / 1537$ \\
\hline Others & 21.8 & $335 / 1537$ \\
\hline Prescribing indicator & & \\
\hline Percentage of patients dispensed & 38.4 & $590 / 1537$ \\
\hline an antibiotic & & \\
\hline No of antibiotics dispensed & & \\
\hline No antibiotic & 61.6 & $947 / 1537$ \\
\hline One antibiotic & 35.8 & $551 / 1537$ \\
\hline Two antibiotics & 2.5 & $39 / 1537$ \\
\hline & & Continued \\
\hline
\end{tabular}

Table 1 Continued

Variables

Percentage $n_{i} / n_{k}{ }^{*} \dagger$

${ }^{*} n_{i}$ numerator.

$\dagger n_{k}$ denominator.

‡Diseases or conditions included: fever: fever and pyrexia.

Cough: cough, dry cough and allergic cough. Respiratory

infections: acute respiratory infection, respiratory infection, chest infection and bronchitis. Loss of appetite: weakness, anorexia and loss of appetite. Skin infections: boils, dermatitis, wound and skin infection. Common cold: common cold and sinusitis. Injury: injuries. Acid peptic disease: acid peptic diseases, gastritis, peptic ulcer and upper gastrointestinal bleeding. Body ache: body ache and backache. Heart disease: heart disease and hypertension. Fungal infection: fungal infection and ring worm. Skin disease: skin diseases and skin allergy. Abdomina discomfort: abdominal pain, nausea, vomiting and dyspepsia. Arthritis and bone pain: arthritis, joint pain, leg pain and shoulder pain.

DDA, Department of Drug Administration;

antibiotic, and registration status and education of pharmacists (table 4 ). Patients $<15$ years were more likely than all other age groups to receive antibiotics $(p \leq 0.001)$. Those patients who attended a pharmacy without a prescription from a doctor or health worker were less likely to receive antibiotics than patients with a prescription $(p \leq 0.001)$. In addition, patients were less likely to receive antibiotics from pharmacists who had a diploma or bachelors in pharmacy $(\mathrm{p}=0.001)$ compared with unlicensed drug retailers or licensed retailers with training from DDA only. The interaction term shows that patients who presented with no prescription were more likely to receive an antibiotic if they presented with no prescription to a pharmacy attended by a trained pharmacist.

\section{DISCUSSION}

In most developing countries, private pharmacies or drug stores are the first point of contact for people seeking healthcare. ${ }^{2}$ Antibiotics (and other prescription medicines) are readily available with or without prescription, and self-medication by patients is common. Non-prescription use of antibiotics is associated with a risk of inappropriate use due both to failure in dispensing in accordance with clinical guidelines and patients not using the drug appropriately. ${ }^{30}$ It is also one of the drivers of the emergence of antimicrobial resistance. ${ }^{31}$

Findings of this study show the overuse of antibiotics dispensed from private pharmacies, with the percentage of patients dispensed an antibiotic (38\%) being considerably higher than the level recommended by the WHO $(20 \%-26.8 \%){ }^{29}$ This finding of overuse is consistent with studies conducted in private facilities in other LMICs including $43 \%$ in both India ${ }^{32}$ and Uganda ${ }^{33}$ and $53 \%$ in Bangladesh. $^{34}$

Unlicensed pharmacies, especially outside of cities, often exist in LMICs. ${ }^{35}$ These pharmacies sell medicines informally and are not legally recognised by the health system of the countries in which they operate. ${ }^{36}$ 
Table 2 Commonly dispensed antibiotics

\begin{tabular}{|c|c|c|c|c|c|c|c|}
\hline & Dispensed antibiotics & No & $\%$ & & $\begin{array}{l}\text { Dispensed antibiotic } \\
\text { classes }\end{array}$ & No & $\%$ \\
\hline 1 & Cefixime & 106 & 16.9 & 1 & Cephalosporins & 239 & 38.0 \\
\hline 3 & Cefpodoxime & 65 & 10.3 & 3 & Quinolones & 86 & 13.7 \\
\hline 4 & Ampicillin+cloxacillin & 55 & 8.7 & 4 & Marcolides & 51 & 8.1 \\
\hline 7 & Metronidazole & 48 & 7.6 & & Total & 629 & 100 \\
\hline 8 & Amoxicillin+clavulanate & 31 & 4.9 & & & & \\
\hline 9 & Cefadroxil & 16 & 2.5 & & & & \\
\hline 10 & Cephalexin & 16 & 2.5 & & & & \\
\hline 14 & Cefixime+clavulanic acid & 11 & 1.7 & & & & \\
\hline 15 & Other & 61 & 9.7 & & & & \\
\hline Total & & 629 & 99.6 & & & & \\
\hline
\end{tabular}

While, practicing healthcare without a license is illegal in Nepal, ${ }^{17}$ weak regulatory oversight of the Nepalese health system encourages pharmacies to operate without licences. This study found the level of dispensing of antibiotics was higher by unlicensed drug retailers and drug retailers with limited training. Interestingly, the interaction term in the multivariable model suggests that, while this is the case, if patients presented to a pharmacy with a trained pharmacist without a prescription, they were more likely to receive antibiotics. It has been suggested that drug retailers may approach dispensing of medicines as any other sales job, not wanting a customer to leave without making a purchase. ${ }^{35}$ More generally, inappropriate dispensing of antibiotics may occur due to the business motive of private pharmacies with profits from antibiotics contributing to total profit. ${ }^{37}$

Third-generation cephalosporins were the most common antibiotic type recommended and dispensed with or without prescription. The finding is consistent with the studies conducted in India showing cephalosporins were the most commonly supplied class of antibiotic in private pharmacies or clinics ${ }^{32}$ and often used by urban private health facilities. ${ }^{38}$ Guidelines often advise that cephalosporins should be avoided as a first-line treatment when a narrower spectrum antibiotic would be effective because they increase the risk of Clostridium difficile, methicillin-resistant Staphylococcus aureus and other resistant infections. ${ }^{39} 40$ Noticeably, third-generation cephalosporins were dispensed to patients with minor symptoms, such as fever, which is self-limiting in most cases and could be a common symptom of several infections. The popularity of third-generation cephalosporins lies in their lesser allergenic and toxicity risks as well as having a broad spectrum of activity. ${ }^{39}$ In Nepal, treatment guidelines do not recommend cephalosporins as a firstline treatment for several infections such as respiratory tract infections, enteric fever, pneumonia and urinary tract infections. ${ }^{41}$

Overprescribing and overuse of antibiotics in the treatment of respiratory infections and diarrhoea is a worldwide problem, potentially leading to widespread antimicrobial resistance. ${ }^{42}$ Contrary to international recommendations, this study found high prescribing rates of antibiotics for both conditions, suggesting possible overprescribing. The WHO guidelines recommend oral rehydration solution with other supplements for non-bloody diarrhoea ${ }^{43}$ and home care without antibiotics for children with respiratory symptoms. ${ }^{44}$

Across all conditions collectively, antibiotics were more likely to be dispensed to younger age groups especially $<15$ years of age compared with older groups. Respiratory diseases and diarrhoea impose a considerable health burden especially to children in LMICs, ${ }^{45} 46$ and may lead to antibiotics being used more widely for the treatment of these diseases. ${ }^{48}$ Higher self-medication practices among younger age groups could also be a factor contributing to higher antibiotic dispensing for younger age groups, with a study in Albania finding an association between self-medication and a higher use of antibiotics among younger age groups. ${ }^{49}$ Additionally, increased education has been found to increase the risk of self-medication with antibiotics, ${ }^{50}$ and globally the literacy rates of young adults is higher than the elderly, with the differences even wider in developing countries. $^{51}$ 


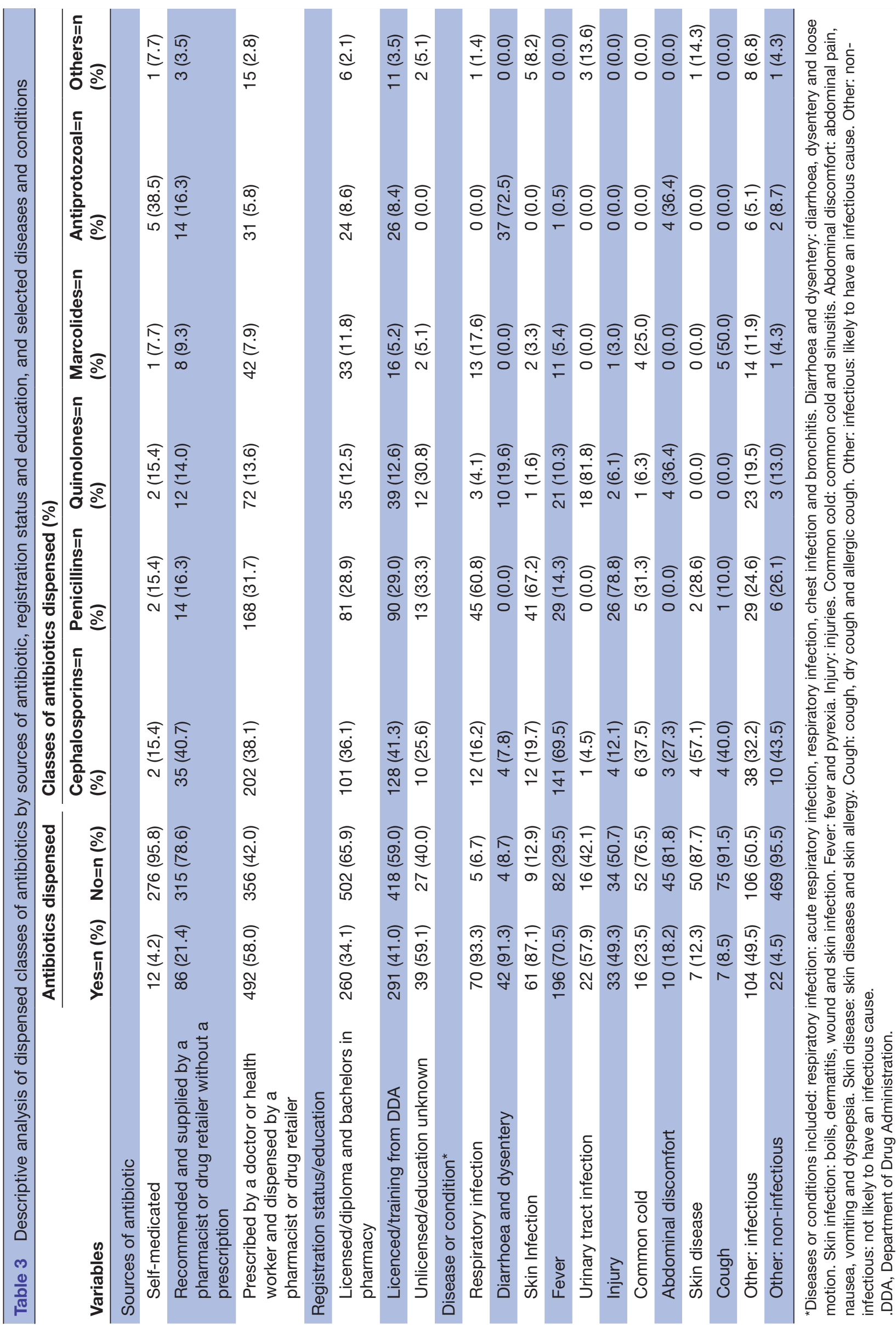




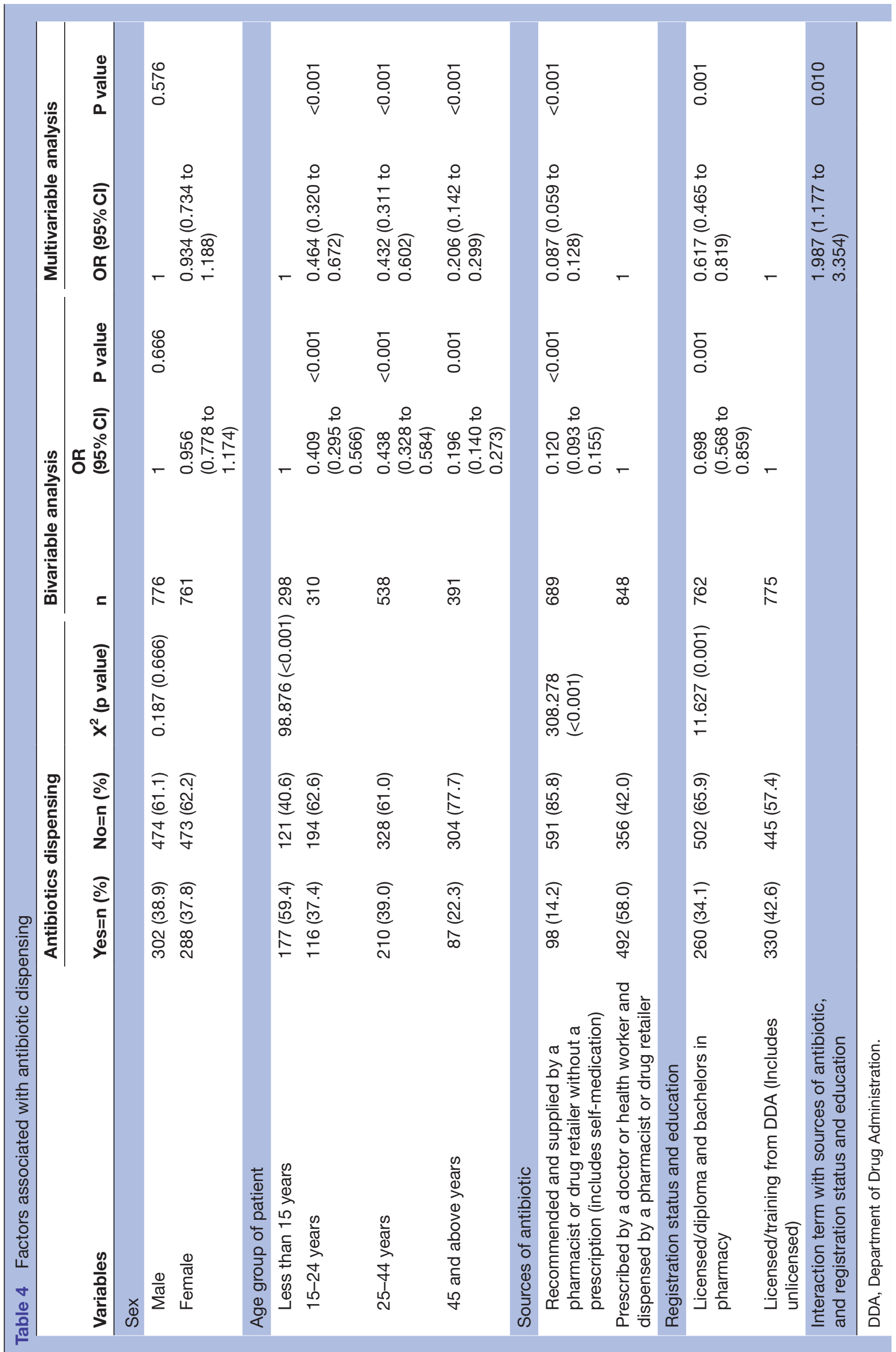




\section{Policy implications}

Levels of antibiotic prescribing above the WHO recommended rate suggests the need to implement measures to reduce potential inappropriate use in Nepal. Almost half of patients were dispensed antibiotics by drug retailers who, unlike pharmacists are professionally trained and do not have formal education in dispensing medicines. While this study did not examine their technical competencies, drug retailers should be encouraged to increase their skills through continued professional education.

In Nepal, prescribing is conducted by physicians and non-physicians such as auxiliary health workers and health assistants, who have 18 months to 3 years postsecondary training in diagnostics and therapeutics, and nurses. ${ }^{52}$ The physicians work at hospitals and non-physicians, who are referred to as health workers, mostly work in public health facilities at the community level and have their own private pharmacies. Health workers are less qualified than physicians but are authorised to prescribe medicines as outlined in the antibiotic treatment guidelines. ${ }^{41}$ However, such guidelines are barely in practice or monitored. ${ }^{53}$ WHO's guideline of good pharmacy practices confines the role of pharmacists to dispensing only. ${ }^{54} \mathrm{~A}$ general lack of enforcement of the legislation covering registration of pharmacies and the distribution of antibiotics facilitates the inappropriate use of antibiotics in Nepal. Stronger enforcement mechanisms of pharmacy registration and restricting pharmacists and drug retailers supplying antibiotics without prescription should be established.

Private pharmacies are widely established in most LMICs including Nepal. They are usually considered as a patient's first point of contact and preferred channel to receive health services ${ }^{2}$ particularly given issues relating to the unavailability and inaccessibility of quality of care from public health facilities. ${ }^{55}$ Private pharmacists and community members are often known to each other and pharmacists can be under pressure to supply antibiotics. ${ }^{56}$ Pharmacists and drug retailers generally do not charge consultation fees and profits from selling drugs is a main source of their income, ${ }^{57}$ which could encourage the selling of antibiotics since it is one of the more profitable medicines. ${ }^{37}$ A targeted intervention to provide education and training relating to antimicrobial resistance and supplying antibiotics only with prescriptions will lead to greater consideration of antibiotic dispensing practices based on the standards of good pharmacy practices, thus contributing to a reduction in the risk of development of antibiotic resistance bacteria.

Additionally, the relatively high prescribing rate of third-generation cephalosporins in private health facilities in Nepal is of concern, given that these classes are considered second-line antibiotics in most guidelines. When antibiotic therapy is necessary, the use of narrow-spectrum antibiotics should be used as first-line treatment whenever possible ${ }^{58}$ to prevent drug-resistant bacteria developing. Educational interventions to reduce inappropriate dispensing or prescribing of antibiotics in unwarranted situations should include guidance on the proper selection of antibiotics.

\section{Strengths and limitations}

Limited evidence is available in regard to the pattern of antibiotic dispensing in LMICs. This study has provided an evidence base about the current pattern of antibiotic dispensing from private pharmacies in Nepal, with data on dispensing of medications including antibiotics sourced directly from patients and validated from the dispensed medicines. Data on dispensed medicines were collected from a wide range of private pharmacies including high-end outlets staffed by pharmacists and small outlets staffed by someone without formal health qualifications. The information on dispensed medicines provides a useful baseline against which to measure the effectiveness of future policies and programmes to reduce the level of inappropriate dispensing of antibiotics. The findings of the study also reinforce calls to build a strong regulatory environment in advancing prudent antibiotic use. The findings may also be applicable to other LMICs, where the health system is similar to Nepal.

However, the study has several limitations. The study covered about $8 \%(33 / 423)$ of private pharmacies in the Rupandehi district. While the selection process followed WHO guidelines, these guidelines do not account for the number of facilities in the district, thus the sample of pharmacies selected may not be representative. Interviews were conducted between 09:00 and 17:00 at the selected pharmacies, which excludes patients attending the pharmacies at other times, and exit interviews were based on convenience sampling. Diagnoses or conditions of patients were non-specific and recorded based on the understanding of the patients. Description of diagnoses or conditions were more symptom-based and were grouped into broad categories together with related conditions. Having such broad categories made it difficult to assess appropriate use of antibiotics. It also prevented any investigation of whether antibiotic dispensing and prescribing followed the standard guidelines. Another limitation is that the Rupandehi district lies in a low-land region of Nepal, which has a greater availability of health services than in hill and high-hill regions. Results of the study are thus more generalisable to districts falling in low-land regions than hill and high-hill regions, a factor which needs to be considered in using findings from the study in developing and implementing policy to improve pharmacy practice in Nepal and similar countries.

\section{CONCLUSION}

This study documents antibiotic dispensing practices in private pharmacies in Nepal that were high compared with WHO guidelines. The overuse of antibiotics has been associated with a higher prevalence of antimicrobial resistance. Given global concerns about 
antimicrobial resistance, evidence relating to overuse and misuse in Nepal provides a rationale to consider introducing initiatives to reduce inappropriate use of antibiotics. Additionally, this evidence may be more widely generalisable to other countries with similar health system financing arrangements.

\section{Twitter Suzanne Robinson @Robinsonsuz}

Acknowledgements We thank the staff of the district public health office and private pharmacies in the Rupandehi district for their support and the research assistants for their help in data collection. We also thank all participants who were included in this study for their valuable time and providing us with information about their medication.

Contributors AN designed the study with input from DH, SR and LAS. AN conducted the research including the analysis. DH conducted the coding check. AN drafted the manuscript and DH and LAS edited the manuscript. All authors contributed to revisions and approved the final manuscript.

Funding The research was supported under a Curtin International Postgraduate Research Scholarship (CIPRS) from the Curtin University, Faculty of Health Sciences. Content is the responsibility of the authors and does not necessarily represent the views of the university. The university had no role in the design of the study, data collection, data analysis, interpretation of data, writing of the manuscript or the decision to submit the article for publication.

Competing interests None declared.

Patient consent for publication Not required.

Ethics approval The study was approved by the Human Research Ethics Committee, Curtin University (HRE2017-0394) and the ethics committee of the Nepal Health Research Council (Reg no.189/2017).

Provenance and peer review Not commissioned; externally peer reviewed. Data availability statement Data are available upon reasonable request.

Open access This is an open access article distributed in accordance with the Creative Commons Attribution Non Commercial (CC BY-NC 4.0) license, which permits others to distribute, remix, adapt, build upon this work non-commercially, and license their derivative works on different terms, provided the original work is properly cited, appropriate credit is given, any changes made indicated, and the use is non-commercial. See: http://creativecommons.org/licenses/by-nc/4.0/.

ORCID iD

Anant Nepal http://orcid.org/0000-0002-5214-8379

\section{REFERENCES}

1 World Health Organization. In: Bigdeli M, Peters DH, Wagner AK, eds. Medicines in health systems: advancing access, affordability and appropriate use, 2014.

2 Smith F. The quality of private pharmacy services in low and middle-income countries: a systematic review. Pharm World Sci 2009;31:351-61.

3 Mayhew S, Nzambi K, Pepin J. Pharmacists' role in managing sexually transmitted infections: policy issues and options for Ghana. Health Policy Plan 2001;16:152-60.

$4 \mathrm{Kloos} \mathrm{H}$, Chama T, Abemo D, et al. Utilization of pharmacies and pharmaceutical drugs in Addis Ababa, Ethiopia. Soc Sci Med 1986;22:653-72.

5 Berendes S, Heywood P, Oliver S, et al. Quality of private and public ambulatory health care in low and middle income countries: systematic review of comparative studies. PLoS Med 2011;8:e1000433.

6 Taber JM, Leyva B, Persoskie A. Why do people avoid medical care? A qualitative study using national data. $J$ Gen Intern Med 2015;30:290-7.

7 Auta A, Hadi MA, Oga E, et al. Global access to antibiotics without prescription in community pharmacies: a systematic review and meta-analysis. Journal of Infection 2019;78:8-18.

8 Holloway K, Van Dijk L. The world medicines situation 2011. rational use of medicines. Geneva: WHO, 2011.

9 World Health Organization. The world medicines situation report 2011, 2011.
10 Michael CA, Dominey-Howes D, Labbate M. The antimicrobial resistance crisis: causes, consequences, and management. Frontiers in Public Health 2014;2.

11. Harbarth S, Samore MH. Antimicrobial resistance determinants and future control. Emerg Infect Dis 2005;11:794-801.

12 Levy S. Antibiotic resistance-the problem intensifies. Adv Drug Deliv Rev 2005;57:1446-50

13 Livermore DM. Bacterial resistance: origins, epidemiology, and impact. Clin Infect Dis 2003;36:S11-23.

14 Gyawali S, Rathore DS, Adhikari K, et al. Pharmacy practice and injection use in community pharmacies in Pokhara City, Western Nepal. BMC Health Serv Res 2014;14:190.

15 Ranjit E. Pharmacy practice in Nepal. Can J Hosp Pharm 2016;69:493

16 Ansari M, Alam K. Pharmacy practice in Nepal. pharmacy practice in developing countries. Elsevier, 2016: 147-68.

17 Ministry of Health and Population. Nepal pharmaceutical country profile. Kathmandu, Nepal: Ministry of Health and Population, World Health Organization, 2011.

18 Ansari M. Evaluation of community pharmacies regarding dispensing practices of antibiotics in two districts of central Nepal. PLoS One 2017;12:e0183907.

19 Wachter DA, Joshi MP, Rimal B. Antibiotic dispensing by drug retailers in Kathmandu, Nepal. Trop Med Int Health 1999;4:782-8.

20 District Public Health Office. Annual Repport. Bhairahawa, Rupandehi, Nepal: District Public Health Office Rupandehi, 2015.

21 Central Bureau of Statistics. National population census 2011, household and population by sex ward level, Rupandehi. Thapathali, Kathmandu: Central Bureau of Statistics, 2012.

22 Central Bureau of Statistics. National population and housing census 2011 (village development Committee/Municipality). Kathmandu, Nepal: Central Bureau of Statistics, 2014.

23 Central Bureau of Statistics. National population and Houing census 2011 (national report. Thapathali, Kathmandu: Central Bureau of Statistics, 2012.

24 World Health Organization. Who operational package for assessing, monitoring and evaluating country pharmaceutical situations: guide for coordinators and data collectors. Geneva, Switzerland: World Health Organization, 2007.

25 World Health Organization, Health Action International. Measuring medicine prices, availability, affordability and price components. 2nd edition. Switzerland: World Health Organization and Health Action International, 2008.

26 University of Denever. Colorado (United States of America) Available: http://www.du.edu/research-scholarship/media/ documents/qualtricsofflinesurveysdocumentation.pdf [Accessed 08 Aug 2019].

27 Zoorob R, Grigoryan L, Nash S, et al. Nonprescription antimicrobia use in a primary care population in the United States. Antimicrob Agents Chemother 2016;60:5527-32.

28 Coates ARM, Halls G, Hu Y. Novel classes of antibiotics or more of the same? Br J Pharmacol 2011;163:184-94.

29 Isah AO, Ross-Degnan D, Quick J, et al. The development of standard values for the who drug use prescribing indicators: ICUM/ EDM/WHO. Available: http://archives.who.int/prduc2004/rducd/ ICIUM_Posters/1a2_txt.htm [Accessed 08 Aug 2019].

30 Lu Y, Hernandez P, Abegunde D, et al. The world medicines situation 2011. Geneva: Medicine expenditures World Health Organization, 2011.

31 Tangcharoensathien V, Chanvatik S, Sommanustweechai A. Complex determinants of inappropriate use of antibiotics. Bull World Health Organ 2018;96:141-4.

32 Kotwani A, Holloway K. Trends in antibiotic use among outpatients in New Delhi, India. BMC Infect Dis 2011;11:99.

33 Mukonzo JK, Namuwenge PM, Okure G, et al. Over-The-Counter suboptimal dispensing of antibiotics in Uganda. J Multidiscip Healthc 2013;6:303.

34 Saha S, Hossain MT. Evaluation of medicines dispensing pattern of private pharmacies in Rajshahi, Bangladesh. BMC Health Serv Res 2017; $17: 136$

35 Buckley GJ, Gostin LO. Countering the problem of falsified and substandard drugs. National Academies Press, 2013.

36 Wafula FN, Goodman CA. Are interventions for improving the quality of services provided by specialized drug shops effective in subSaharan Africa? A systematic review of the literature. Int J Qual Health Care 2010;22:316-23.

37 Nga DTT, Chuc NTK, Hoa NP, Hoa NQ, et al. Antibiotic sales in rural and urban pharmacies in northern Vietnam: an observational study. BMC Pharmacol Toxicol 2014;15.

38 Chandy SJ, Thomas K, Mathai E, et al. Patterns of antibiotic use in the community and challenges of antibiotic surveillance in a lower- 
middle-income country setting: a repeated cross-sectional study in Vellore, South India. J Antimicrob Chemother 2013;68:229-36.

39 Dancer SJ. The problem with cephalosporins. J Antimicrob Chemother 2001;48:463-78.

40 Wilcox MH, Chalmers JD, Nord CE, et al. Role of cephalosporins in the era of Clostridium difficile infection. Journal of Antimicrobial Chemotherapy 2017;72:1-18.

41 Kafle K. National Antibiotic Treatment Guidelines - 2014 (Technical Report). Ministry of Health and Population, Government of Nepal, 2014.

42 Boonstra E, Lindbaek M, Ngome E. Adherence to management guidelines in acute respiratory infections and diarrhoea in children under 5 years old in primary health care in Botswana. Int J Qual Health Care 2005;17:221-7.

43 World Health Organization. The treatment of diarrhoea: a manual for physicians and other senior health workers. The treatment of diarrhoea: a manual for physicians and other senior health workers: World Health Organization, 1995.

44 World Health Organization. Revised who classification and treatment of childhood pneumonia at health facilities-Evidence summaries. Geneva: World Health Organization, 2014.

45 Forum of International Respiratory Societies. The global impact of respiratory Diseasese. 2nd edn. Sheffield: European Respiratory Society, 2017.

46 Platts-Mills JA, Babji S, Bodhidatta L, et al. Pathogen-Specific burdens of community diarrhoea in developing countries: a multisite birth cohort study (MAL-ED). Lancet Glob Health 2015;3:e564-75.

47 Pernica JM, Steenhoff AP, Welch H, et al. Correlation of clinical outcomes with multiplex molecular testing of stool from children admitted to hospital with gastroenteritis in Botswana. $J$ Pediatric Infect Dis Soc 2016;5:312-8.

48 Pavlinac PB, Denno DM, John-Stewart GC, et al. Failure of Syndrome-Based Diarrhea Management Guidelines to Detect Shigella Infections in Kenyan Children. J Pediatric Infect Dis Soc 2016;5:366-74.

49 Jorgji K, Bebeci E, Apostoli P, et al. Evaluation of use of antibiotics without prescription among young adults in Albania case study: Tirana and Fier district. Hippokratia 2014;18:217.

50 Chang J, Wang Q, Fang Y. Socioeconomic differences in selfmedication among middle-aged and older people: data from the China health and retirement longitudinal study. BMJ Open 2017;7:e017306.

51 Roser M, Ortiz-Ospina E. Literacy. Our World in Data, 2016.

52 Sherchand JB. Human resources for health $(\mathrm{HRH})$ and challenges in Nepal. J Inst Med 2013;35.

53 Shrestha S, Yadav RS, Deo SK. Burgeoning irrational antibiotics use in primary health care in Nepal. J Nepal Health Res Counc 2019;16:473-5.

54 World Health Organization, International Pharmaceutical Federation. Joint FIP/WHO guidelines on good pharmacy practice. Standards for Quality of Pharmacy Services, 2011.

55 Peters DH, Garg A, Bloom G, et al. Poverty and access to health care in developing countries. Ann N Y Acad Sci 2008;1136:161-71.

56 Saradamma RD, Higginbotham N, Nichter M. Social factors influencing the acquisition of antibiotics without prescription in Kerala state, South India. Soc Sci Med 2000;50:891-903.

57 Abbas B. Health for the rural Masses-Insights from Chakaria, 2009.

58 Davies S. Chief medical officer annual report 2011: antimicrobial resistance. Department of Health and Social Care, 2014. 